\title{
Trends and determinants of complementary feeding practices in Tanzania, 2004-2016
}

Felix Akpojene Ogbo ${ }^{1,2^{*}}$, Pascal Ogeleka ${ }^{2}$ and Akorede O. Awosemo ${ }^{2}$

\begin{abstract}
Background: Following the successful implementation of the Millennium Development Goals (MDGs) strategy in Tanzania, improvements in child health indicators were observed. However, it remains unclear whether complementary feeding practices have improved given the renewed global agenda on child nutrition. This study investigated trends and socioeconomic and health service factors of complementary feeding practices in Tanzania for the period spanning from 2004 to2016.
\end{abstract}

Methods: The study was based on the Tanzania Demographic and Health Survey data for the years 2004-2005 $(n=2480), 2010(n=2275)$ and 2015-2016 $(n=2949)$ to estimate the trends in complementary feeding practices. Multivariate logistic regression models that adjusted for year of the survey, clustering and sampling weights were used to investigate the association between the modifiable study factors (socioeconomic and health service factors) and complementary feeding practices among children aged 6-23 months in Tanzania.

Results: Over the study period, minimum dietary diversity (MDD) and minimum acceptable diet (MAD) have worsened from 46\% (95\% confidence interval [95\% Cl] 41.5-50.7\%) in 2004-2005 to 30\% (95\% Cl 25.7-32.9\%) in 2015-2016 and 16.9\% (95\% Cl 14.9-18.9\%) in 2004-2005 to 6.0\% (95\% Cl 4.9-7.1\%) in 2015-2016, respectively. Minimum meal frequency (MMF) remained unchanged, 37\% in 2004-2005 and 2015-2016. The introduction of solid, semi-solid and soft foods improved from 79\% (95\% Cl 74.5-83.9\%) in 2004-2005 to 87\% (95\% Cl 83.7-90.9\%) in 2015-2016. Multivariate analyses revealed that higher maternal education and household wealth, mother's employment, health facility birthing and postnatal care (PNC) visit were associated with MDD, MAD and MMF. Traditional birth attendant-assisted births and PNC visits were associated with the introduction of complementary foods. In contrast, birthing in the health facility was associated with the delayed introduction of complementary foods.

Conclusion: Between 2004 and 2016, the prevalence and determinants of complementary feeding practices varied in Tanzania. Improving complementary feeding practices is feasible in Tanzania given the renewed focus on child nutrition in the country. Child nutrition policy interventions should target all mothers, particularly mothers from low socioeconomic background and those with limited access to health services to maximise results.

Keywords: Complementary feeding, Determinants, Malnutrition, Tanzania, Infant and young child, Trends

\footnotetext{
*Correspondence: felgbo@yahoo.co.uk; f.ogbo@westernsydney.edu.au

${ }^{1}$ Translational Health Research Institute (THRI), School of Medicine, Western

Sydney University, Campbelltown Campus, Locked Bag 1797, Penrith, NSW

2571, Australia

${ }^{2}$ Prescot Specialist Medical Centre, Welfare Quarters, Makurdi, Benue State,

Nigeria
}

(c) The Author(s). Open Access This article is distributed under the terms of the Creative Commons Attribution 4.0 International License (http://creativecommons.org/licenses/by/4.0/), which permits unrestricted use, distribution, and reproduction in any medium, provided you give appropriate credit to the original author(s) and the source, provide a link to the Creative Commons license, and indicate if changes were made. The Creative Commons Public Domain Dedication waiver (http://creativecommons.org/publicdomain/zero/1.0/) applies to the data made available in this article, unless otherwise stated. 


\section{Background}

Exclusive breastfeeding (EBF) for infants aged less than 6 months is essential for growth and development; however, the breast milk alone is not adequate to meet the nutritional needs of the infant after the age of 6 months, indicating the need to introduce complementary foods [1]. The World Health Organization (WHO) recommends complementary feeding, defined as the introduction of nutritionally appropriate and safe foods for infants aged 6 months and above to supplement breastfeeding [1, 2]. Appropriate complementary feeding practices reduce the risk of childhood undernutrition (i.e. stunting, wasting and being underweight) [3], diarrhoea [4-6] and under-five mortality [3]. Despite the demonstrated benefits of appropriate complementary feeding practices, inappropriate complementary feeding is still widespread in many developing countries [7-9], including Tanzania $[10,11]$, with subsequent negative impact on child health and survival [3].

In Tanzania, complementary feeding practices are suboptimal as they do not meet the four WHO-recommended complementary feeding indicators (introduction of solid, semi-solid and soft foods; minimum dietary diversity; minimum meal frequency; and minimum acceptable diet) [12]. This is despite the adoption of the Global Strategy on Infant and Young Child Feeding (IYCF) [12] and the implementation of the Millennium Development Goal (MDG) strategies to improve child survival [13]. Previous studies based on the 1999 and 2010 nationwide surveys in Tanzania had elucidated some factors associated with inappropriate complementary feeding practices $[10,11]$. These factors included the child's age (6-11 months), limited access to mass media, lower level of paternal and maternal education, poor socioeconomic status and the paucity of postnatal check-ups. However, no nationally representative studies have examined trends in complementary feeding practices nor has there been an investigation of socioeconomic and health service factors associated with complementary feeding practices during the MDG period (2000-2015) in Tanzania. The exposition of trends in complementary feeding in Tanzania would show which complementary feeding practices are improving or decreasing in their distribution. This information is required to identify issues relating to complementary feeding practices and also to inform the effectiveness of current IYCF interventions.

Notably, Tanzania was one of the few countries that met the key MDG indicators (such as reduction in under-five mortality) globally [13, 14]. Investigating the trends and factors associated with complementary feeding practices would be essential to policy decision-makers and nutrition experts to provide targeted interventions. Similarly, findings from this study will also be of high importance to public health experts in Tanzania given the current United Nations Decade of Action on Nutrition (2016-2025) [15] and Sustainable Development Goal-2 (SDG-2) agenda, which has a strong global political commitment to end malnutrition in all its forms by 2030 [16]. This study aimed to investigate the trends and socioeconomic and health service determinants of complementary feeding practices in Tanzania between 2004 and 2016.

\section{Method}

\section{Data source}

This study utilised data from the Tanzania Demographic and Health Survey (TDHS) for the years 2004-2005, 2010 and 2015-2016, which were collected by the Tanzania National Bureau of Statistics (NBS), Dar es Salaam, in collaboration with the US Inner City Fund (ICF) International, MD. The TDHS provides comprehensive information on complementary feeding practices, and other child and maternal socioeconomic and health characteristics, obtained from a nationally representative sample of households. During the surveys, a stratified two-stage cluster design was used to select the samples, and standardised face-to-face questionnaires were administered to eligible women of childbearing age (15-49 years). The number of households selected in the surveys included $N=10,312$ in 2004-2005, $N=9623$ in 2010 and $N=13,360$ in 2015-2016, with response rates that ranged from 96 to $98.8 \%$. Further details on the data source, including sampling technique and method of data collection, are described in the respective TDHS reports [12, 17, 18].

In accordance with the TDHS approach [12], the WHO definitions for assessing complementary feeding practices in populations [2] and previously published studies $[7,10,19]$, the analyses were restricted to the youngest living child aged $0-23$ months, living with respondents (women aged 15-49 years). A weighted total sample of 7705 eligible women who met the complementary feeding criteria was used for the study (that is, $n=2480$ for $2004-2005, n=2275$ for 2010 and $n=2949$ in 2015-2016).

\section{Outcome variables}

The outcome variables were the complementary feeding indicators (introduction of solid, semi-solid or soft foods; minimum dietary diversity; minimum meal frequency; and minimum acceptable diet), measured using the WHO definition for assessing IYCF practices [2].

- Introduction of solid, semi-solid or soft foods: The proportion of infants 6-8 months of age who received solid, semi-solid or soft foods.

- Minimum dietary diversity (MDD): The proportion of children 6-23 months of age who received foods from four or more food groups. The seven food 
groups used for tabulation of this indicator were grains, roots and tubers; legumes and nuts; dairy products (milk, yoghurt, cheese); flesh foods (meat, fish, poultry and liver/organ meats); eggs; vitamin A-rich fruits and vegetables; and other fruits and vegetables.

- Minimum meal frequency (MMF): The proportion of breastfed and non-breastfed children 6-23 months of age, who received solid, semi-solid or soft foods (including milk feeds for non-breastfed children); the minimum number of times or more (i.e. two times for breastfed infants 6-8 months, three times for breastfed children 9-23 months and four times for non-breastfed children 6-23 months in the previous day). "Meals" include both meals and snacks (other than trivial amounts), and frequency is based on caregiver report.

- Minimum acceptable diet (MAD): The proportion of children 6-23 months of age who received both minimum dietary diversity and minimum meal frequency. All indicators were based on a 24-h recall of the infant's dietary intake by the mother.

\section{Exposure variables}

The selection of the study factors was based on evidence from previous studies conducted in sub-Saharan Africa and South Asia [7, 10, 20-22], where modifiable socioeconomic and health service factors were associated with inappropriate complementary feeding practices. Those studies also suggested that these modifiable factors are essential in formulating specific policy efforts to improve complementary feeding practices. The socioeconomic factors included mother's and father's highest educational level, household wealth index and employment status. Health service factors included the delivery assistance, place of delivery, the number of antenatal and postnatal clinic visits.

\section{Analytic strategy}

The analysis followed a similar approach employed in previously published studies [23, 24]. First, initial analyses involved the description of the study factors, the estimation of a series of frequencies and cross-tabulations to estimate the prevalence of complementary feeding practices from 2004 to 2016 and by the study factors (socioeconomic and health service variables). Second, univariate logistic regression analyses were employed to examine the probable factors associated with complementary feeding practices. Third, only those variables with a $P$ value $<0.1$ were entered into the multivariate models that adjusted for confounders (maternal marital status, sex of the baby, birth order and interval, geographical region, place of residence and maternal age) to investigate the factors associated with complementary feeding practices in Tanzania. In the models of socioeconomic factors, an additional adjustment was made for health service factors as confounders of the association between socioeconomic factors and complementary feeding indicators. A similar strategy was used in models of health service factors, where additional adjustment for socioeconomic factors was performed. The regression analyses were conducted separately for both the year-specific data (i.e. 2004-2005, 2010, and 2015-2016) and the combined dataset to examine any differences in the determinants.

Additionally, the TDHS data from 2004 to 2016 were combined in the analyses for the following reasons: (i) to assess the trends and modifiable determinants of complementary feeding practices during the MDG era in order to provide specific and relevant complementary feeding information to help policy decision-makers during the implementation of the United Nations action on nutrition and SDG-2 agenda; (ii) to create a unique opportunity to compare complementary feeding outcomes over time and (iii) to increase the statistical power of the study. In the models, adjustment for year of the survey in the combined dataset, as well as cluster variations and sampling weights in both the year-specific data and combined dataset, was conducted $[25,26]$. The weighted frequencies, the prevalence of complementary feeding practices by year, the odds ratios (OR) and their corresponding 95\% confidence intervals for both the year-specific data and the combined dataset were reported. All analyses were conducted in Stata, version 15.0 (StataCorp, College Station, TX, USA).

\section{Ethics}

The national health research body in Tanzania (the Medical Research Coordinating Committee, MRCC) granted Measure DHS/ICF International granted the ethical approval to conduct the surveys. The questionnaires used during the surveys were approved by the ICF International Institutional Review Board (IRB) to ensure they met the US Department of Health and Human Services regulations for the protection of human participants as well as the host country's IRB, to ensure compliance with national laws. The data used are available to apply for online, and approval was obtained from Measure DHS/ICF International for this analysis.

\section{Results}

\section{Characteristics of the study participants}

Between 2004 and 2016, the majority of mothers were employed while many mothers had no schooling. Many mothers had four or more ANC visits from 2004 to 2016. In contrast, many mothers made no PNC visits over the study period (Table 1 ). 
Table 1 Characteristics of the study population

\begin{tabular}{|c|c|c|c|c|c|c|}
\hline & $2004-2005(N=2480)$ & & $2010(N=2275)$ & & $2015-2016(N=2949)$ & \\
\hline & $n$ & $\%$ & $n$ & $\%$ & $n$ & $\%$ \\
\hline \multicolumn{7}{|l|}{ Socioeconomic factors } \\
\hline \multicolumn{7}{|l|}{ Mother's employment } \\
\hline Not working & 349 & 14.1 & 301 & 13.2 & 656 & 22.3 \\
\hline Working & 2130 & 85.9 & 1974 & 86.8 & 2293 & 77.7 \\
\hline \multicolumn{7}{|l|}{ Mother's education } \\
\hline No schooling & 652 & 26.3 & 573 & 25.2 & 575 & 19.5 \\
\hline Primary education & 1711 & 68.9 & 1522 & 66.9 & 1865 & 63.3 \\
\hline Secondary and above education & 116 & 4.8 & 180 & 7.9 & 507 & 17.2 \\
\hline \multicolumn{7}{|l|}{ Father's education } \\
\hline No schooling & 432 & 18.6 & 381 & 18.0 & 330 & 13.7 \\
\hline Primary education & 1716 & 73.6 & 1526 & 71.8 & 1653 & 68.5 \\
\hline Secondary and above education & 183 & 7.8 & 217 & 10.2 & 430 & 17.8 \\
\hline \multicolumn{7}{|l|}{ Household wealth } \\
\hline Poor & 1121 & 45.2 & 1033 & 45.4 & 1334 & 45.2 \\
\hline Middle & 996 & 40.2 & 890 & 39.2 & 1107 & 37.5 \\
\hline Rich & 362 & 14.6 & 351 & 15.4 & 509 & 17.3 \\
\hline \multicolumn{7}{|l|}{ Health service factors } \\
\hline \multicolumn{7}{|l|}{ Place of delivery } \\
\hline Home & 1293 & 52.1 & 1106 & 48.6 & 1001 & 34.0 \\
\hline Health facility & 1187 & 47.9 & 1169 & 51.4 & 1948 & 66.0 \\
\hline \multicolumn{7}{|l|}{ Postnatal visits } \\
\hline None & 2282 & 92.1 & 1512 & 66.4 & 1860 & 63.1 \\
\hline $0-2$ days & 150 & 6.0 & 549 & 24.2 & 122 & 4.1 \\
\hline 3-42 days & 46 & 1.9 & 214 & 9.4 & 966 & 32.8 \\
\hline \multicolumn{7}{|l|}{ Antenatal visits } \\
\hline None & 78 & 3.1 & 60 & 2.6 & 74 & 2.5 \\
\hline $1-3$ & 927 & 37.3 & 1257 & 55.2 & 1392 & 47.2 \\
\hline $4+$ & 1473 & 59.6 & 958 & 42.1 & 1482 & 50.3 \\
\hline \multicolumn{7}{|l|}{ Delivery assistance } \\
\hline Health professional & 1151 & 48.6 & 1147 & 51.4 & 385 & 40.8 \\
\hline Traditional birth attendance & 217 & 9.1 & 282 & 12.6 & 5 & 0.6 \\
\hline Other untrained personnel & 999 & 42.2 & 803 & 36.0 & 551 & 58.6 \\
\hline
\end{tabular}

$n$ and $\%$ are the weighted count and proportion for each variable, respectively

Trends in complementary feeding practices in Tanzania, 2004-2016

The proportion of mothers who introduced solid, semi-solid and soft foods to infants aged 6-8 months increased from $79 \%$ (95\% confidence interval [95\% CI] 74.5-83.9\%) in 2004-2005 to 92\% (95\% CI 88.4-94.9\%) in 2010 but worsened slightly to $87 \%$ (95\% CI 83.790.9\%) in 2015-2016 (Fig. 1). Between 2004 and 2016, a significant declining trend was observed among Tanzanian children who met the MDD and MAD from $46 \%$ (95\% CI $41.5-50.7 \%)$ in $2004-2005$ to $30 \%$ (95\% CI
25.7-32.9\%) in 2015-2016 and $16.9 \%$ (95\% CI 14.9$18.9 \%$ ) in $2004-2005$ to $6 \%$ (95\% CI $4.9-7.1 \%$ ) in $2015-$ 2016, respectively. However, MMF remained unchanged over the study period $(37.0 \%, 95 \%$ CI $33.1-41.1 \%)$ in 2004-2005 and 2015-2016, despite a significant decrease in 2010 (26.2\%, 95\% CI 23.0-29.5\%) (Fig. 1).

\section{Determinants of complementary feeding practices Introduction of solid, semi-solid or soft foods}

Mothers who delivered their babies in the health facility were less likely to introduce solid, semi-solid or soft 


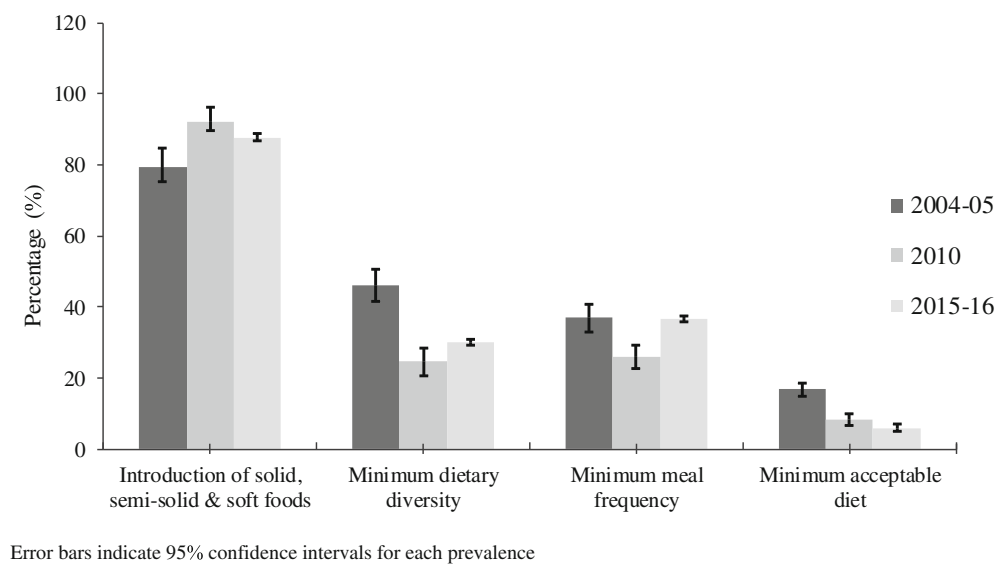

Fig. 1 Prevalence of complementary feeding practices in Tanzania, 2004-2016

foods to infants aged 6-8 months compared to those who delivered at home between 2004 and 2016 (Table 2). Receiving delivery assistance from a traditional birth attendant (TBA) was associated with delayed introduction of solid, semi-solid or soft foods compared to receiving assistance from health professionals. Mothers who had an early postnatal clinic (PNC, within 0-2 days) visit were more likely to introduce solid, semi-solid and soft foods to their infants aged 6-8 months compared to those who made no PNC visits over the study period. The year-specific data analyses showed no significant association between the study factors and the introduction of solid, semi-solid and soft foods (Additional file 1: Table S1).

\section{Minimum dietary diversity}

Between 2004 and 2016, children whose mothers had primary and higher educational level and those from wealthier households (middle and higher household wealth category) were more likely to meet MDD compared to those whose mothers had no schooling and from poorer households, respectively (Table 2). Similarly, children whose mothers were employed, those who birthed in a health facility and had PNC visit between 3 and 42 days were more likely to meet MDD compared to mothers with no employment, those whose mothers birthed at home and had no PNC visit, respectively (Table 2). Father's higher education (secondary and higher) was associated with meeting the MDD compared to those whose fathers had no education. In the year-specific analyses, children whose mothers had higher educational attainment and those from wealthier households were more likely to meet MDD compared to those whose mothers had no education and those from poorer households, respectively (Additional file 2: Table S2). Similarly, children whose mothers birthed in a health facility were more likely to meet MDD compared to those whose mothers birthed at home, but the association was not evident in 2010.

\section{Minimum meal frequency}

The study showed that children whose mothers had secondary and higher educational level, those whose mothers were employed and those from richer households were more likely to meet MMF compared to those whose mothers had no schooling, were not in employment and were from poorer households from 2004 to 2016, respectively. Children whose mothers who made PNC visits were more likely to meet MMF compared to those whose mothers made no PNC visits (Table 3). The year-specific analyses showed that children whose mothers had early PNC ( $0-2$ days) visits had higher odds for meeting MMF compared to those whose mothers had no PNC visits (Additional file 3: Table S3).

\section{Minimum acceptable diet}

In the pooled dataset, children whose mothers had secondary and higher education, those who were employed and those from middle and richer households were more likely to meet MAD compared to those whose mothers had no schooling, were not in employment and were from poorer households, respectively (Table 3). Children whose mothers who had early PNC ( $0-2$ days) visits and those who birthed in the health facility were more likely to meet the MAD compared to those whose mothers reported no PNC visits and birthed at home, respectively (Table 3). The year-specific data analyses showed no significant association between the study factors and MAD (Additional file 4: Table S4).

\section{Discussion}

The prevalence of introduction of solid, semi-solid and soft foods improved between 2004 and 2010 but 
Igbo et al. Tropical Medicine and Health $\quad$ (2018) $46: 40$

Page 6 of 13

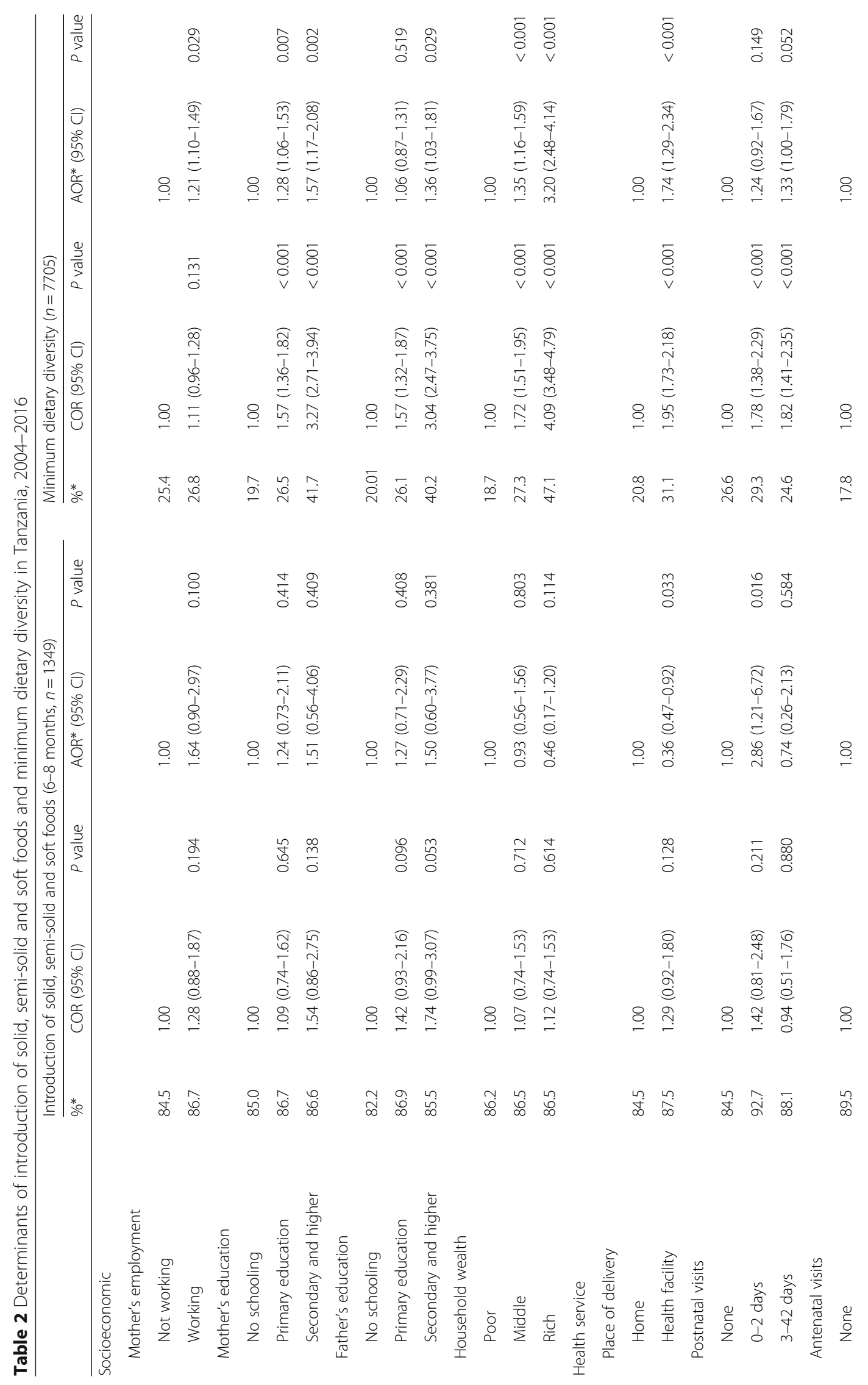




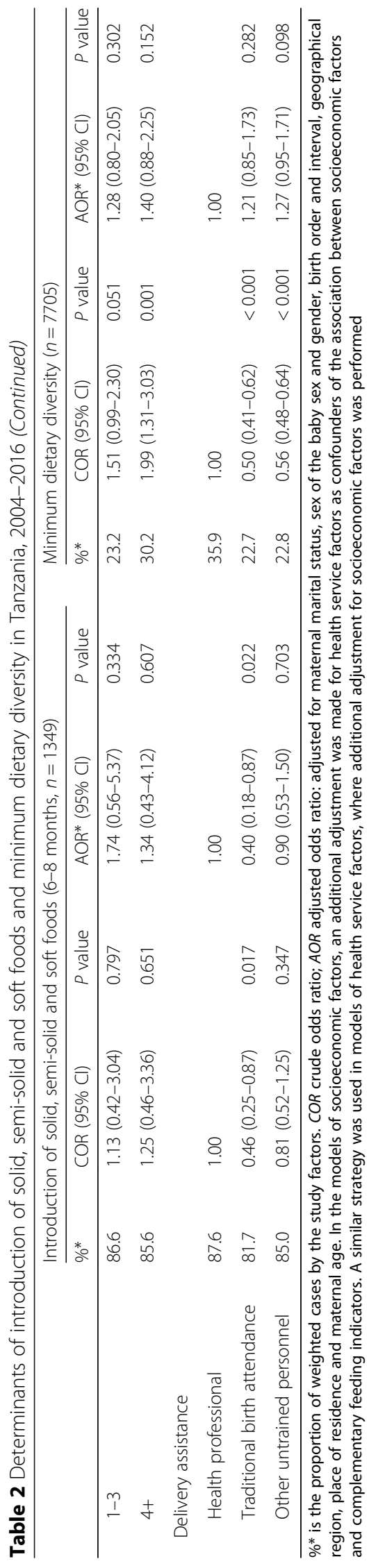


Igbo et al. Tropical Medicine and Health $\quad$ (2018) $46: 40$

Page 8 of 13

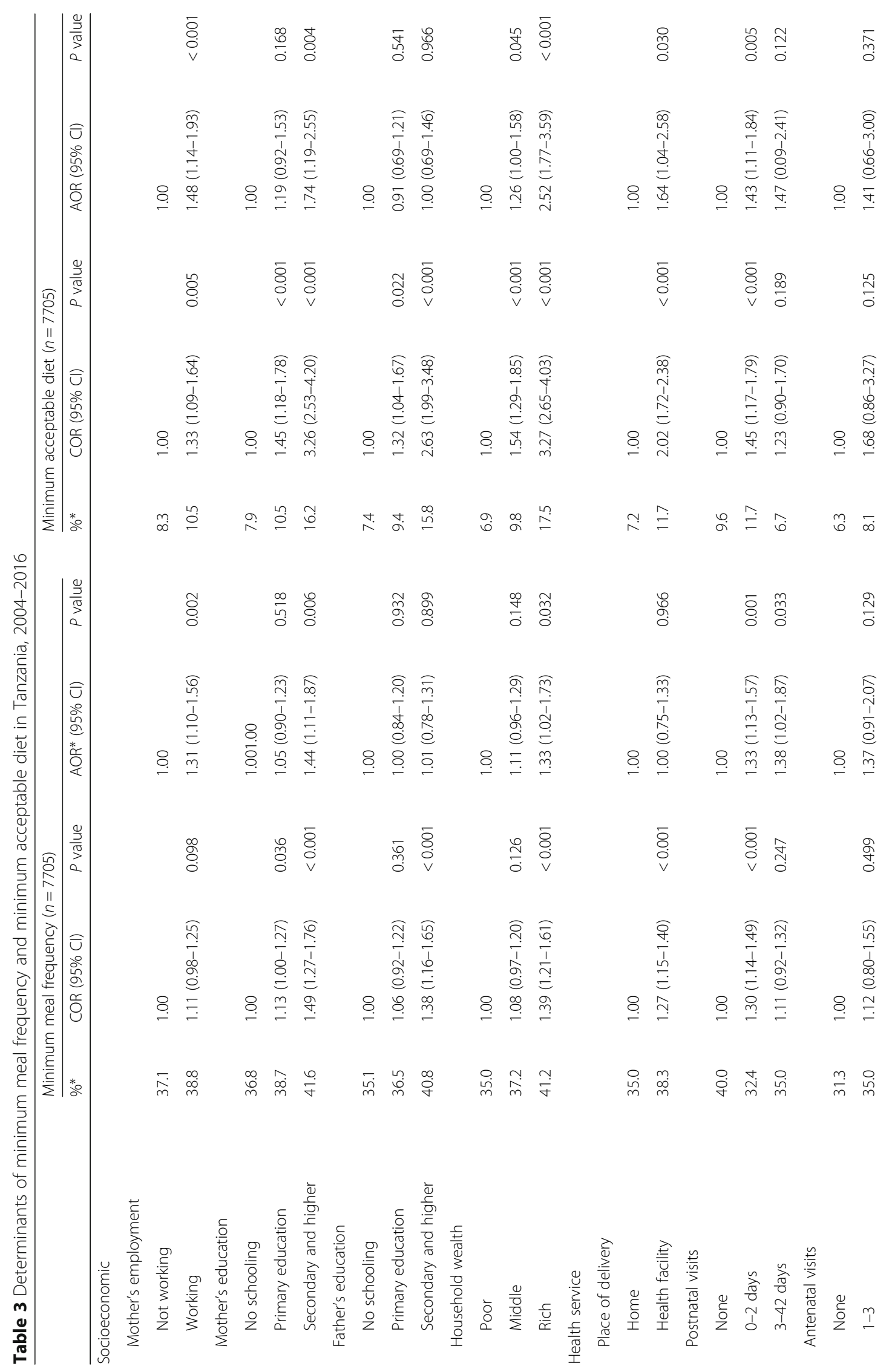




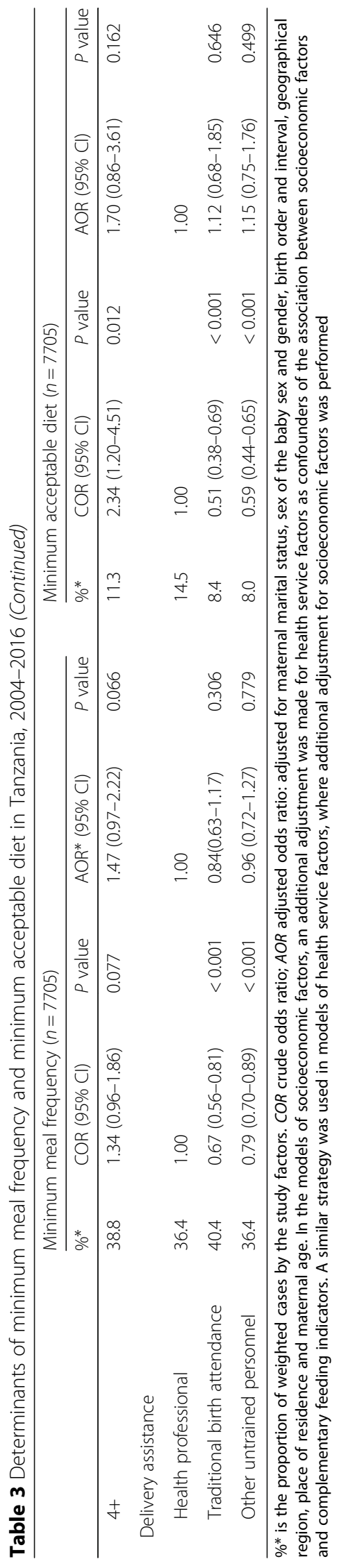


decreased slightly in 2015-2016. Notably, a worsening trend was evident for MDD and MAD among Tanzanian children from 2004 to 2016. In contrast, the prevalence of MMF remained unchanged over the study period, despite a significant drop in 2010. The determinants of each of the complementary feeding indicators varied widely in the year-specific data and the pooled dataset.

Globally, higher maternal education is one of the most important factors needed to improve maternal and child health [27], including child nutrition [25, 28, 29] as articulated in the SDG-4 agenda, which aims to ensure that all girls and boys complete quality primary and secondary education by 2030 [16]. Higher maternal education increases a mother's employment opportunity and household decision-making process [30] and is associated with an increase in health service use and reduced risk of maternal death [31]. The present study found that higher maternal education was associated with MDD, MMF and MAD. Similarly, higher household wealth and maternal employment were associated with MDD, MMF and MAD, possibly indicating the strong association between higher maternal education, improved household wealth and employment status [32, 33]. Our findings suggest that Tanzania may not only improve complementary feeding practices if the SDG-4 agenda is achieved, but also has the potential to increase the broader child health measures. Drawing lessons from the successful implementation of the MDG would also be crucial in the rollout of the current national nutrition strategic plan and SDG agenda in Tanzania.

Birthing in the health facility has significant benefit for both the mother and infant, including increased likelihood of the mother to engage in optimal infant feeding behaviours [26]. However, the present study found that birthing in a health facility in Tanzania was associated with the delayed introduction of solid, semi-solid or soft foods to infants aged 6-8 months. This finding is inconsistent with similar national studies conducted in Nigeria [7] and five South Asian countries-Bangladesh, India, Nepal, Pakistan and Sri Lanka [22, 34], which found no association between place of delivery and introduction of solid, semi-solid or soft foods. In comparison to sub-Saharan African countries with high diarrhoea mortality, Tanzania had the highest EBF prevalence (63\%) [26], where mothers were likely to continue EBF instead of introducing complementary foods at aged 6-8 months as recommended. This practice of EBF beyond 6 months may be a likely reason for why mothers delay the introduction of complementary foods to their infants in Tanzania [6]. Additional plausible reasons for why birthing in a health facility was associated with the delayed introduction of complementary foods may include a lack of knowledge of appropriate complementary feeding practices among healthcare workers or issues around staff training or poor information transfer between healthcare workers and mothers [35]. Our finding implies that nutrition experts in Tanzania need to design specific interventions (such as appropriate complementary feeding practice messages) for mothers who birth in a health facility, and policy decision-makers need to adopt evidence-based approaches to improve child nutrition training for healthcare workers.

The study revealed that an early PNC visit (0-2 days) was associated with the introduction of complementary foods, despite the marginal drop in the prevalence from 2010 to 2016. For MDD and MAD, the evidence was somewhat mixed, where 3-42 days and 0-2 days PNC visits were associated with MDD and MAD, respectively. In addition, any PNC visit was associated with an increased likelihood of children aged 6-23 months to meet the MMF. These findings are similar to previously published studies conducted in Nigeria [7], Bangladesh, India, Nepal, Pakistan and Sri Lanka [22, 34], where no PNC visit was associated with inappropriate complementary feeding practices. In Tanzania, postnatal care services for both the mother and her baby involve the assessment of the baby (e.g. for danger signs), provision of IYCF information to the mother, cord examination and other services, including temperature measurement for the newborn and promotion of immunisation [12, 17]. Between 2004 and 2015 , there was an improvement in the number of women who made PNC visits in Tanzania [12, 17]. Nevertheless, this increase in post-birth visits to a healthcare professional did not translate to improvement in the prevalence of MDD and MAD in the present study. Policy interventions that target women during the early post-birth period may be very helpful in improving the proportion of children who receive safe and nutritionally balanced complementary foods in Tanzania.

Our study suggests that Tanzania's gains in maternal and child health indicators during the MDG era were not reflected in the MDD and MAD given the declining trend in these outcome measures. In Tanzania (like many sub-Saharan African countries), developmental assistance for health (DAH) plays a significant role in financing relevant public health programmes [28, 36-38]. The decline in MDD and MAD over the study period may be attributed to a shift in DAH from maternal and child health interventions (including child nutrition efforts) to HIV/ AIDS programmes in sub-Saharan African countries $[28,37,38]$, which was reasonably appropriate given the high HIV/AIDS burden in those countries. The decline may also be due to the adverse weather conditions that contribute to low farm outputs, farmers' poor post-harvest food management systems and subsequently food insecurity $[39,40]$. The present study also found that TBA-assisted births were associated with early introduction of complementary foods, while health 
facility birthing was associated with an increased likelihood of meeting MDD and MAD. During the MDG period, TBA-assisted births improved compared to relative/friend-assisted births in Tanzania [12, 17] due to an array of regional and national strategic initiatives implemented by the Government of Tanzania, including the National Road Map Strategic Plan to Accelerate Reduction of Maternal, Newborn and Child Deaths in Tanzania [41]. However, whether these interventions may have translated into optimal complementary feeding practices in the country remains unclear. Additional studies that focus on the impact of those programmes and place of delivery on complementary feeding practices may be warranted to elucidate the extent to which the place of birth impacts complementary feeding practices in Tanzania.

Currently, Tanzania is well-positioned given the strong political commitment to achieve the United Nations nutrition targets and SDGs, as well as the dedication to improve complementary feeding practices among children aged 0-23 months, with likely impact on child undernutrition in the short and long term. This is possible because of the contextualisation of global health actions on child nutrition in the country. For example, in 2016, the Tanzanian Government introduced the National Multisectoral Nutrition Action Plan (NMNAP, 2016-2021), with the improvement of complementary feeding practices being part of the aim for the strategy [42]. Nevertheless, nutrition efforts in Tanzania must be designed to translate the strong political will into appropriately resourced and locally relevant interventions that also consider the availability and accessibility of local food types and health services to mothers [6, 42]. Also, studies that examine the nutritional contents of local food types, particularly in poorly resourced communities, may be needed to guide context-specific health promotion messages in Tanzania.

This study has several limitations. First, the outcome variables were measured based on self-reported information. This is a possible source of measurement bias (including social desirability) in which mothers may have erroneously recall when, how and with what the child (0-23 months) was fed during the survey, or they may respond to questions in a manner that satisfies the interviewer. Second, misclassification in the study factors may also have occurred, where, for example, the number of ANC visits may have been over- or underestimated. This could result in over- or underestimation of the association between the health service variable and complementary feeding indicators. Third, as with the analysis of cross-sectional data, the interpretation of the causality between the study factors and complementary feeding practices is impossible. Finally, our results may also be limited given that we were unable to adjust for all contextual factors (such as family dynamics, a cultural belief system for child feeding and health system characteristics) that might affect the complementary feeding practices. Despite these limitations, the study has strengths. We believe that selection bias may be less likely to be present in this study given the high response rates in the surveys (96-98.8\%). The TDHS data were collected by trained personnel who used standardised questionnaires that allow comparability across time. Our study provides locally relevant evidence on trends and determinants of complementary feeding practices during the MDG period to guide renewed efforts to improve child nutrition in Tanzania.

\section{Conclusion}

The current study indicated that MDD and MAD have worsened between 2004 and 2016, but MMF remained unchanged. The introduction of solid, semi-solid and soft foods improved marginally. Common determinants of complementary feeding practices included higher maternal education and household wealth, mother's employment, health facility birthing, PNC visits and TBA-assisted births for the introduction of complementary foods. Our findings suggest that Tanzania could improve complementary feeding practices given the current nutrition policy interventions. However, the translation of those policy decisions into measurable nutrition achievements is essential to improve child health outcomes.

\section{Additional files}

Additional file 1: Table S1. Introduction of solid, semi-solid and softs foods by socioeconomic and health service characteristics, Tanzania 2004-2016. (DOCX $21 \mathrm{~kb}$ )

Additional file 2: Table S2. Minimum dietary diversity by socioeconomic and health service characteristics, Tanzania 2004-2016. (DOCX $21 \mathrm{~kb}$ )

Additional file 3: Table S3. Minimum meal frequency by socioeconomic and health service characteristics, Tanzania 2004-2016. (DOCX 21 kb)

Additional file 4: Table S4. Minimum acceptable diet by socioeconomic and health service characteristics, Tanzania 2004-2016. (DOCX $21 \mathrm{~kb})$

\section{Abbreviations}

EBF: Exclusive breastfeeding; ICF: Inner City Fund; IYCF: Infant and Young Child Feeding; MAD: Minimum acceptable diet; MDD: Minimum dietary diversity; MDG: Millennium Development Goal; MMF: Minimum meal frequency; NBS: National Bureau of Statistics; SDG: Sustainable Development Goal; TBA: Traditional birth attendant; TDHS: Tanzania Demographic and Health Survey; WHO: World Health Organization

\section{Acknowledgements}

The authors are grateful to Measure DHS, ICF International, Rockville, MD, USA, for providing the data for the analysis.

\section{Funding}

This study received no specific grant from any funding agency in public, commercial or not-for-profit sectors. 


\section{Availability of data and materials}

The analysis was based on the datasets collected for the Tanzania Demographic and Health Survey. Information on the data and content can be assessed at http://www.dhsprogram.com/data/available-datasets.cfm.

\section{Authors' contributions}

FAO conceptualised the study, analysed and interpreted the data, drafted the original manuscript and critically revised the final manuscript as submitted. PO contributed to the conceptualisation of the study and drafting of the original manuscript, interpreted the results and critically revised the manuscript as submitted. AA contributed to the data interpretation and critical revision of the manuscript as submitted. All authors read and approved the final manuscript as submitted.

\section{Ethics approval and consent to participate}

Measured DHS/ICF International obtained ethical approval from the Medica Research Coordinating Committee in Tanzania. All questionnaires used for the DHS were approved by the ICF International Institutional Review Board (IRB) to ensure that they met the US Department of Health and Human Services regulations for the protection of human participants as well as the host country's IRB, to ensure compliance with national laws. The datasets used are available to apply for online, and approval was obtained from the Measure DHS/ICF International for the analysis.

\section{Consent for publication}

Not applicable

\section{Competing interests}

The authors declare that they have no competing interests.

\section{Publisher's Note}

Springer Nature remains neutral with regard to jurisdictional claims in published maps and institutional affiliations.

Received: 30 July 2018 Accepted: 2 November 2018

Published online: 20 November 2018

\section{References}

1. World Health Organization. The Global Strategy for Infant and Young Child Feeding. Geneva: WHO; 2003.

2. World Health Organization. Indicators for assessing Infant and Young Child Feeding practices. Geneva: WHO; 2008.

3. Black R, Allan LH, Bhutta ZA, Caulfield LE, de Onis M, Ezzati M, et al. The Maternal and Child Undernutrition Study Group: maternal and child undernutrition: global and regional exposures and health consequences. Lancet. 2008;371:243-60.

4. Ogbo FA, Agho K, Ogeleka P, Woolfenden S, Page A, Eastwood J. Infant feeding practices and diarrhoea in sub-Saharan African countries with high diarrhoea mortality. PLoS One. 2017:12(2):e0171792.

5. Ogbo FA, Page A, Idoko J, Claudio F, Agho KE. Diarrhoea and suboptimal feeding practices in Nigeria: evidence from the national household surveys. Paediatr Perinat Epidemiol. 2016;30:346-55.

6. Ogbo FA, Nguyen $\mathrm{H}, \mathrm{Naz} \mathrm{S}$, Agho KE, Page A. The association between infant and young child feeding practices and diarrhoea in Tanzanian children. Trop Med Health. 2018:46:2.

7. Ogbo FA, Page A, Idoko J, Claudio F, Agho KE. Trends in complementary feeding indicators in Nigeria, 2003-2013. BMJ Open. 2015;5(10):e008467.

8. Patel A, Pusdekar Y, Badhoniya N, Borkar J, Agho KE, Dibley MJ. Determinants of inappropriate complementary feeding practices in young children in India: secondary analysis of National Family Health Survey 20052006. Matern Child Nutr. 2012;8(s1):28-44.

9. Dibley MJ, Roy S, Senarath U, Patel A, Tiwari K, Agho KE, et al. Acrosscountry comparisons of selected infant and young child feeding indicators and associated factors in four South Asian countries. Food Nutr Bull. 2010; 31(2):366-79.

10. Victor R, Baines SK, Agho KE, Dibley MJ. Factors associated with inappropriate complementary feeding practices among children aged 6-23 months in Tanzania. Matern Child Nutr. 2014;10(4):545-61.

11. Hussein A. Breastfeeding and complementary feeding practices in Tanzania. East Afr J Public Health. 2005;2(1):27-31.
12. National Bureau of Statistics (NBS) [Tanzania] and ICF International. Demographic and Health Survey and Malaria Indicator Cluster Survey 201516. Dar es Salaam: NBS and ICF International; 2015-2016.

13. Afnan-Holmes $\mathrm{H}$, Magoma M, John T, Levira F, Msemo G, Armstrong CE, et al. Tanzania's countdown to 2015: an analysis of two decades of progress and gaps for reproductive, maternal, newborn, and child health, to inform priorities for post-2015. Lancet Glob Health. 2015;3(7):e396-409.

14. United Nations. The Millennium Development Goals report 2015. New York: United Nations; 2015.

15. United Nations General Assembly. The UN Decade of Action on Nutrition: working together to implement the outcomes of the Second International Conference on Nutrition. New York: United Nations; 2016.

16. United Nations. Sustainable Development Goals online: United Nations; 2016. [cited 201828 July ]. Available from: http://www.un.org/ sustainabledevelopment/sustainable-development-goals/

17. National Bureau of Statistics (NBS) [Tanzania] and ICF Macro. Tanzania Demographic and Health Survey 2004-05. Dar es Salaam: Tanzania and ICF Macro: National Bureau of Statistics and ICF Macro; 2005.

18. National Bureau of Statistics (NBS) [Tanzania] and ICF Macro. Tanzania Demographic and Health Survey 2010. Dar es Salaam: NBS and ICF Macro; 2011.

19. Agho KE, Ezeh OK, Ogbo FA, Enoma Al, Raynes-Greenow C. Factors associated with inadequate receipt of components and use of antenatal care services in Nigeria: a population-based study. Int Health. 2018;10(3):172-81.

20. Madise NJ, Mpoma M. Child malnutrition and feeding practices in Malawi. Food Nutr Bull. 1997;18(2):190-201.

21. Kimani-Murage EW, Madise NJ, Fotso J-C, Kyobutungi C, Mutua MK, Gitau TM, et al. Patterns and determinants of breastfeeding and complementary feeding practices in urban informal settlements, Nairobi Kenya. BMC Public Health. 2011;11(1):396.

22. Senarath U, Agho KE, Akram DE, Godakandage SS, Hazir T, Jayawickrama $H_{\text {, }}$ et al. Comparisons of complementary feeding indicators and associated factors in children aged 6-23 months across five South Asian countries. Matern Child Nutr. 2012;8(s1):89-106.

23. Ogbo FA, Eastwood J, Hendry A, Jalaludin B, Agho KE, Barnett B, et al. Determinants of antenatal depression and postnatal depression in Australia. BMC Psychiatry. 2018;18(1):49.

24. Leigh B, Milgrom J. Risk factors for antenatal depression, postnatal depression and parenting stress. BMC Psychiatry. 2008;8(1):1.

25. Ogbo FA, Page A, Agho KE, Claudio F. Determinants of trends in breastfeeding indicators in Nigeria, 1999-2013. Public Health Nutr. 2015;18:3287-99.

26. Ogbo FA, Eastwood J, Page A, Efe-Aluta O, Anago-Amanze C, Kadiri EA, et al. The impact of sociodemographic and health-service factors on breastfeeding in sub-Saharan African countries with high diarrhoea mortality. Public Health Nutr. 2017;20(17):3109-19.

27. Güneş PM. The role of maternal education in child health: evidence from a compulsory schooling law. Econ Educ Rev. 2015:47:1-16.

28. Ogbo FA, Page A, Idoko J, Claudio F, Agho KE. Have policy responses in Nigeria resulted in improvements in infant and young child feeding practices in Nigeria? Int Breastfeed J. 2017;12:9.

29. Liagat P, Rizvi MA, Qayyum A, Ahmed H, Ishtiaq N. Maternal education and complementary feeding. Pak J Nutr. 2006;5(6):563-8.

30. Ahmed S, Creanga AA, Gillespie DG, Tsui AO. Economic status, education and empowerment: implications for maternal health service utilization in developing countries. PLoS One. 2010;5(6):e11190.

31. Karlsen S, Say L, Souza J-P, Hogue CJ, Calles DL, Gülmezoglu AM, et al. The relationship between maternal education and mortality among women giving birth in health care institutions: analysis of the cross sectional WHO Global Survey on Maternal and Perinatal Health. BMC Public Health. 2011; 11(1):606.

32. Urke HB, Bull T, Mittelmark MB. Socioeconomic status and chronic child malnutrition: wealth and maternal education matter more in the Peruvian Andes than nationally. Nutr Res. 2011;31(10):741-7. https://doi.org/10.1016/j. nutres.2011.09.007.

33. Carneiro P, Meghir C, Parey M. Maternal education, home environments, and the development of children and adolescents. J Eur Econ Assoc. 2013; 11 (suppl_1):123-60.

34. Senarath U, Godakandage SS, Jayawickrama H, Siriwardena I, Dibley MJ. Determinants of inappropriate complementary feeding practices in young children in Sri Lanka: secondary data analysis of demographic and health survey 2006-2007. Matern Child Nutr. 2012;8(1):60-77. 
35. Manongi RN, Marchant TC. Improving motivation among primary health care workers in Tanzania: a health worker perspective. Hum Resour Health. 2006;4(1):6.

36. Lee B, Dutta A, Lyimo H, Silaa R, FFutures Group and Health Policy Project. Budget analysis of the Government of Tanzania's Ministry of Health and Social Welfare, fiscal year 2015/2016. Washington, DC: Health Policy Project; 2015.

37. Institute for Health Metrics and Evaluation (IHME). Financing Global Health 2016: development assistance, public and private health spending for the pursuit of universal health coverage. Seattle, WA: IHME; 2017

38. Financing Global Health Visualization [Internet]. University of Washington. 2016 [cited September 7 2016]. Available from: http://vizhub.healthdata.org/fgh/.

39. Abass AB, Ndunguru G, Mamiro P, Alenkhe B, Mlingi N, Bekunda M. Postharvest food losses in a maize-based farming system of semi-arid savannah area of Tanzania. J Stored Prod Res. 2014;57:49-57.

40. Kaminski J, Christiaensen L. Post-Harvest Loss in Sub-Saharan Africa: What Do Farmers Say?. Policy Research Working Paper;No. 6831. World Bank, Washington, DC. @ World Bank. 2014. https://openknowledge.worldbank. org/handle/10986/17721. License: CCBY 3.0 IGO.

41. United Republic of Tanzania. The National Road Map Strategic Plan To Accelerate Reduction of Maternal, Newborn and Child Deaths in Tanzania 2008-2015. Dar es Salaam: Ministry of Health and Social Welfare; 2008

42. United Republic of Tanzania. Tanzania National Multisectoral Nutrition Action Plan (NMNAP) for the period July 2016-June 2021: STRATEGIC PLAN: from evidence to policy to action. Dar Es Salaam: Prime Minister's Office; 2016. Report no

Ready to submit your research? Choose BMC and benefit from:

- fast, convenient online submission

- thorough peer review by experienced researchers in your field

- rapid publication on acceptance

- support for research data, including large and complex data types

- gold Open Access which fosters wider collaboration and increased citations

- maximum visibility for your research: over $100 \mathrm{M}$ website views per year

At BMC, research is always in progress.

Learn more biomedcentral.com/submissions 